\title{
Asymmetric warming over coastal California and its impact on the premium wine industry
}

\author{
Ramakrishna R. Nemani ${ }^{1, *}$, Michael A. White ${ }^{1}$, Daniel R. Cayan ${ }^{2}$, Gregory V. Jones ${ }^{3}$, \\ Steven W. Running ${ }^{1}$, Joseph C. Coughlan ${ }^{4}$, David L. Peterson ${ }^{4}$ \\ ${ }^{1}$ Numerical Terradynamic Simulation Group, University of Montana, Missoula, Montana 59812, USA \\ ${ }^{2}$ Climate Research Division, Scripps Institution of Oceanography and Water Resources Division, United States Geological \\ Survey, La Jolla, California 92093, USA \\ ${ }^{3}$ Department of Geography, Southern Oregon University, Ashland, Oregon 97520, USA \\ ${ }^{4}$ Ecosystem Science \& Technology Branch, NASA/Ames Research Center, Moffett Field, California 94035, USA
}

\begin{abstract}
Climatic changes over coastal California from 1951 to 1997 may have benefited the premium wine industry, as seen in higher quality wines and larger grape yields. Observed temperature warming trends were asymmetric, with greatest warming at night and during spring. Warming was associated with large increases in eastern Pacific sea surface temperatures (SST) and amounts of atmospheric water vapor. Although the average annual temperature warming trend was modest $\left(1.13^{\circ} \mathrm{C} / 47 \mathrm{yr}\right)$, there was a $20 \mathrm{~d}$ reduction in frost occurrence and a $65 \mathrm{~d}$ increase in frost-free growing season length. In the Napa and Sonoma valleys, warmer winter and spring temperatures advanced the start of the growing season by 18 to $24 \mathrm{~d}$, and enhanced atmospheric water vapor resulted in a $7 \%$ reduction in evaporative demand. Given the strong coupling between Pacific SSTs and the coastal California climate, and because regional-scale SSTs persist for 6 to 12 mo, additional research may allow the possibility of predicting vintage quantity and quality from previous winter conditions.
\end{abstract}

KEY WORDS: Climatic change · Asymmetric warming $\cdot$ Growing season length · Wine industry

\section{INTRODUCTION}

Recent climate warming trends, when expressed as annual average increases, tend to be modest $\left(1.0^{\circ} \mathrm{C} / 100 \mathrm{yr}\right)$ and may appear to be insignificant (IPCC 1995). However, warming trends are diurnally and seasonally asymmetric, with greatest warming during nights and in spring (IPCC 1998). On a global scale, increases in atmospheric greenhouse gases $\left(\mathrm{CO}_{2}\right.$, water vapor, methane etc.), changes in land-use, and changes in cloud cover and properties are considered to be responsible for rising temperatures (IPCC 1995). Recent studies also show that asymmetric warming trends may be due to a vigorous hydrologic

*E-mail: nemani@ntsg.umt.edu cycle (i.e. higher amounts of evaporation, atmospheric water vapor, cloud cover and precipitation) tending to increase minimum temperature $\left(T_{\min }\right)$ more than maximum temperature $\left(T_{\max }\right)$ (Chahine 1992, Dai et al. 1997). It is conceivable that warming as a result of rising $\mathrm{CO}_{2}$ levels is further enhanced by the increases in atmospheric water vapor (Raval \& Ramanathan 1989). If such a water vapor feedback mechanism exists, it would most likely appear first in maritime climates.

Ocean and land temperatures are found to co-vary along coastal regions of western North America (Livezey \& Smith 1999). The primary mechanism for such co-variation is the horizontal transport of water vapor (Fig. 1, Gaffen \& Ross 1999). Enhanced water vapor transport from ocean to land first results in increased dewpoint temperature $\left(T_{\text {dew }}\right)$, which raises $T_{\min }$ through the latent heat of condensation. This 


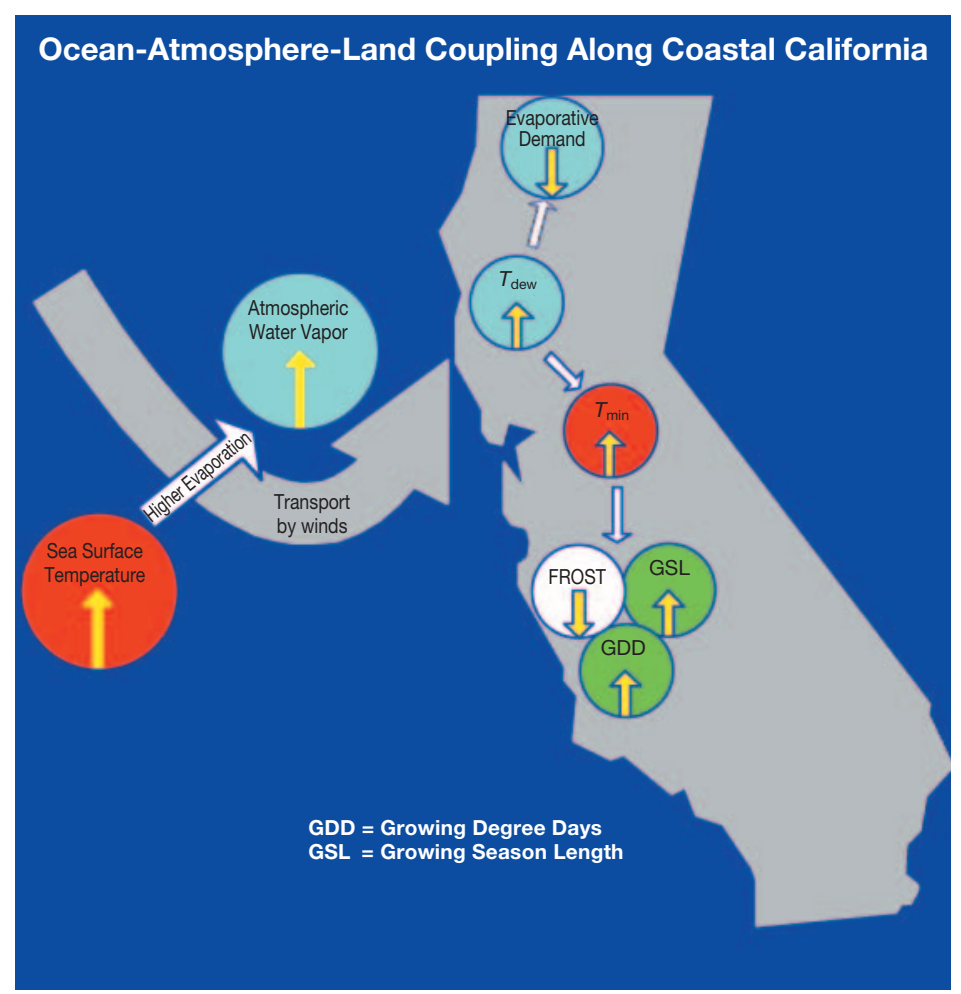

Fig. 1. Schematic showing the causes and consequences of asymmetric warming over coastal California. Increases in atmospheric water vapor, as a result of warmer SSTs over the Pacific Ocean, when transported over land increase $T_{\text {dew }}$ and $T_{\min }$ over coastal California. Changes in $T_{\text {dew }}$ and $T_{\min }$ further modify a number of biophysically important variables: evaporative demand, frost frequency, growing season length (GSL), and growing degree days (GDD) retail wine industry. Grapes grown for wine production (winegrapes Vitis vinifera) respond more directly to long-term climatic variations than more intensively managed crops, because they are less irrigated and fertilized, minimally genetically engineered, and long-lived (>50 yr). Since the early 1950s, winegrape growers in California have seen dramatic increases in premium wine quality, grape yield, and crop value. Past viticultureclimate research indicates that high-quality wines are generally associated with: (1) low frost damage in mild winters (January, February, March); (2) early and even budburst, flowering, and development during warm springs (April, May, June), and (3) optimal maturation with low summer temperature variability (July, August, September) (Gladstones 1992, Jones 1999), Then the following question arises: Have regional climatic changes enabled the phenomenal growth in the Californian wine industry?

Here we report results of our analyses: (1) the co-variability and trends in Pacific Ocean and coastal California temperatures, (2) the long-term climatic changes in premium wine-producing areas of the Napa and Sonoma valleys (NSV), (3) the influence of observed climatic changes on viticulture in coastal California, and (4) the observed trends in California vintages.

\section{DATA ANALYSIS}

\subsection{Pacific climate and coastal California}

As conceptualized in Fig. 1, climatic changes over the Pacific Ocean are hypothesized to have a strong impact on coastal California climate. To study longterm climatic variability over the Pacific Ocean, we used Comprehensive Ocean-Atmosphere Data Set (COADS) of gridded SST, sea level pressure (SLP) and specific humidity $(q)$ from 1951-1997 (Woodruff et al. 1987). The COADS dataset is well documented and widely used in global climate research. To detect trends in SSTs, the conceptualized source of the connection between ocean and land temperatures, we used monthly SSTs from a $5^{\circ} \times 5^{\circ}$ latitude/longitude region centered at $35^{\circ} \mathrm{N}$ and $125^{\circ} \mathrm{W}$, close to central Californian wine-producing areas.

In order to test if increasing SSTs enhance the hydrologic cycle, we used the $q$ estimates from COADS data to estimate the co-variation between SSTs and $q$. For each grid cell over the oceans, we correlated changes 
in SSTs with observed changes in $q$. Both datasets were smoothed with a 3 mo low-pass filter prior to the correlation analysis.

The predominance of low-pressure systems over the Pacific Ocean, especially in winter months, tends to increase southwesterly winds, bringing warm, moist Pacific air over the California coast (Trenberth \& Hurrell 1994). Winters dominated by low SLPs tend to have warm temperatures and cause faster snowmelt and earlier peak streamflows (Dettinger \& Cayan 1995). We used COADS SLP to test if low-pressure systems are associated with the hypothesized changes shown in Fig. 1. We calculated the average number of annual frosts and divided the 1951-1997 dataset into aboveand below-average scenarios. For the 10 most extreme years within each scenario, we then calculated the composite $700 \mathrm{mb}$ pressure patterns.

The co-variability between Pacific SSTs and coastal California temperatures was tested using climate divisional average air temperatures (average of north, central and south coast divisions) available from National Climatic Data Center $(\mathrm{NCDC})$ and SSTs $\left(5^{\circ} \times 5^{\circ}\right.$ area described earlier). Daily $T_{\text {dew }}$ observed at San Diego and San Francisco airports were used to study the changes in atmospheric water vapor transported from the Pacific Ocean as a result of changes in SST and $q$.

Increases in cloud cover, as a result of enhanced hydrologic cycle, are closely associated with the asymmetric warming (Plantico et al. 1994). Enhanced atmospheric water vapor, in addition to increasing $T_{\text {dew }}$ also affects cloud cover. We grouped hourly cloud cover observations at San Francisco airport from 1951-1993 into daytime (07:00 to 19:00 h) and nighttime (19:00 to 07:00 h) cloud cover. While increase in nighttime cloud cover tends to increase $T_{\min }$, daytime cloud cover tends to decrease $T_{\max }$.

\subsection{Napa and Sonoma valleys (NSV)}

We chose NSV in coastal California for an in-depth analysis of climatic changes for the following reasons: (1) NSV are well known for producing some of the best wines in the US, under a strong maritime influence of the Pacific Ocean; (2) the area under winegrape cultivation nearly tripled in Napa valley, from approximately 4000 ha in 1957 to over 12000 ha in 1997. To study trends in the climate of NSV, we used daily climate observations ( $T_{\max }, T_{\min }$ and rainfall) from 4 sites (Napa state hospital, St. Helen, Santa Rosa, and Healdsburg) from 1951-1997. We performed linear regression analysis of annual and monthly $T_{\text {aver }} T_{\max }$ $T_{\min }$ and diurnal temperature range (DTR). Daily data were grouped into winter, spring and summer averages for further seasonal analysis.

\subsection{Climate and viticulture}

Climate regulates nearly every step of wine production, from selection of a suitable grape variety to the type and quality of wines produced (Gladstones 1992). Amount of solar radiation and rainfall, frost intensity and duration, temperature variability, and humidity levels during the growing season impact quality and quantity of grapes produced. Climatically, it is often considered that the major influence on the grapevines is that of microscale effects (Johnson 1985). However, in general, it is the regional circulation and climate regime that controls to a large degree the local or microclimates of a region. Grapevines Vitis vinifera are a phenologically distinct crop with the most important developmental events being bud break, flowering, fruit set, veraison (color change and maturation nascent), harvest (when the grapes are fully mature), and leaf fall. The rate of development between these phenological events varies greatly with each grapevine variety, the climate, and its geographical location. The timing of these developmental stages is also related to the ability of the vine to produce, with early and unhindered phenological events usually resulting in larger yields (Jones 1999). Additionally, the pace by which vines go through their stages has been related to vintage quality, with early harvests generally resulting in higher quality (Jones 1999). The 4 stages, along with the general climatic influences for each stage, can be approximated (for the Northern Hemisphere; Jones 1999) as follows:

- Stage I (bud break and the putting forth of leaves), commencing around mid-March or the first week of April, needs ample soil moisture and sunshine with temperatures above $10^{\circ} \mathrm{C}$ for sustained vegetative growth. Frost or freeze occurrence can reduce bud fruitfulness leading to poor yields and quality.

- Stage II (floraison or flowering), occurring in the first few weeks of June, needs dry, stable conditions to not hinder flower growth.

- Stage III (veraison or the development of the grape and its maturation), beginning near the end of July or the first week of August, this stage needs dry conditions to limit moisture-induced grape rot with moderate temperatures, high levels of insolation and low temperature variability to concentrate sugars leading up to harvest.

- Stage IV (dormancy from harvest) occurs generally in late September through mid-October and leaf fall over the winter months leading back to bud break. This stage needs sufficiently cold temperatures to initiate latent bud hardening with limited freeze damage.

In order to study the impact of climatic changes, we estimated a number of biophysically meaningful variables for viticulture (frost frequency, growing degree 
days [GDD], vapor pressure deficits [VPD], growing season length [GSL]) from daily climatic data. Frost frequency is estimated as the number of days in a year with $\mathrm{T}_{\min }<0.0^{\circ} \mathrm{C}$. Use of GDD is quite common in agriculture for predicting various phenological stages (budburst, flowering, crop maturity, Went 1953) and pest/disease outbreaks. GDD are calculated as accumulated heat units above a base temperature set at $10^{\circ} \mathrm{C}$ for grapes (Coombe 1987). GSL (days) is estimated as the duration between the last spring frost and the first fall frost.

We calculated VPD as the difference in vapor pressures at $T_{\text {dew }}$ and $T_{\max }$ during the growing season (March-October). Based on a strong relation $(\mathrm{R}=0.96$, $\left.\mathrm{p}<0.001 T_{\text {dew }}=-0.35+0.98 T_{\text {min }}\right)$ between observed $T_{\text {dew }}$ and $T_{\text {min }}$ during the growing season along the west coast of US, we assumed that $T_{\text {min }}=T_{\text {dew }}$ at NSV (Gaffen \& Ross 1999).

Spring warming and decline in frosts advance the start of growing seasons (Myneni et al. 1997). Since there were no obtainable long-term datasets on winegrape phenology in NSV, we used the GDD concept to estimate the date of winegrape flowering. Previous studies in Napa valley have established that flowering in winegrapes occurs when vines accumulate about 425 GDD from January 1 (McIntyre et al. 1987). For each year (1951-1997), we calculated the date of flowering using the GDD approach.

Phenological observations (budbreak, flowering, etc.) from a network of honeysuckle plants are available from 4 sites in NSV from 1968-1994 (Caprio 1993). We used the date of flowering from these observations to evaluate ecosystem responses to the observed climatic changes, as well as to check our grapevine flowering estimates from the GDD approach.

\subsection{California vintages}

Advances in viticultural practices (irrigation, nutrition, pest/disease control, trellising, etc.) and experience in wine making have certainly contributed to the recent success of California vintages (Jackson \& Lombard 1993). In spite of such advances, wine growers generally believe climate plays an important role in determining the quantity and quality of a given vintage. While vintage quantity can be directly measured as yield ha ${ }^{-1}$, vintage quality measures are difficult and subjective. We used yields ha ${ }^{-1}$ reported for Napa valley (Napa County Agricultural Commissioner 1997) to estimate trends in vintage quantity between 1951 and 1997 . Wine ratings, in spite of being subjective, have a significant economic impact. For example, analysis of Wine Spectator data (http://www.winespectator.com) showed that for 1995 Napa wines, a rating increase of 10 points on a scale from
0 to 100 translated to a $220 \%$ increase in price per bottle. Wine ratings produced immediately after production, such as Sotheby's (Stevenson 1997) and the Wine Spectator ratings (Laube 1996) are more indicative of climatic influences than are ratings updated on a yearly basis (Parker 1997). Since long-term current-year ratings were not available specifically for north coast wines and because the Laube ratings are on a limited 1 to 5 scale, we used Sotheby's system (1 to 100 scale) in this study. Sotheby's ratings available from 1963-1996 represent average wine quality for the entire California premium wine industry, which is dominated by premium wines from NSV.

\section{RESULTS AND DISCUSSION}

\subsection{Co-variability and trends in Pacific and coastal California climates}

Trends (1951-1997) in annual average Pacific SSTs show a warming of $0.72{ }^{\circ} \mathrm{C} / 47 \mathrm{yr}$ (Fig. 2). A shift in SSTs is also evident, starting in 1976, which is well documented and associated with a number of environmental changes over western North America (Ebbesmeyer et al. 1990). Some recent studies have speculated that the 1976-77 shift is a part of a larger circulation pattern, the Pacific Decadal Oscillation (McGowan et al. 1998), which seems to have intensified since 1976, resulting in a number of frequent El Niño events (Trenberth \& Hoar 1997).

A strong correlation between SSTs and $q$ was observed over much of the northern latitude oceans (Fig. 3), indicating that the hydrological cycle does become vigorous with increasing SSTs. Winter anom-

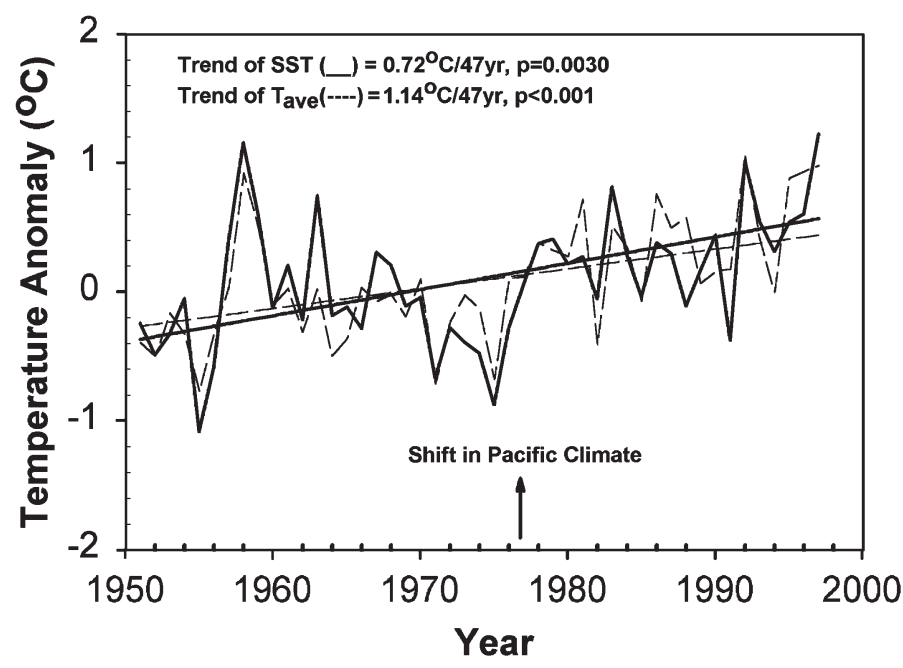

Fig. 2. Anomalies of coastal California $T_{\text {ave }}$ and Pacific SSTs from their 1960-1990 averages 


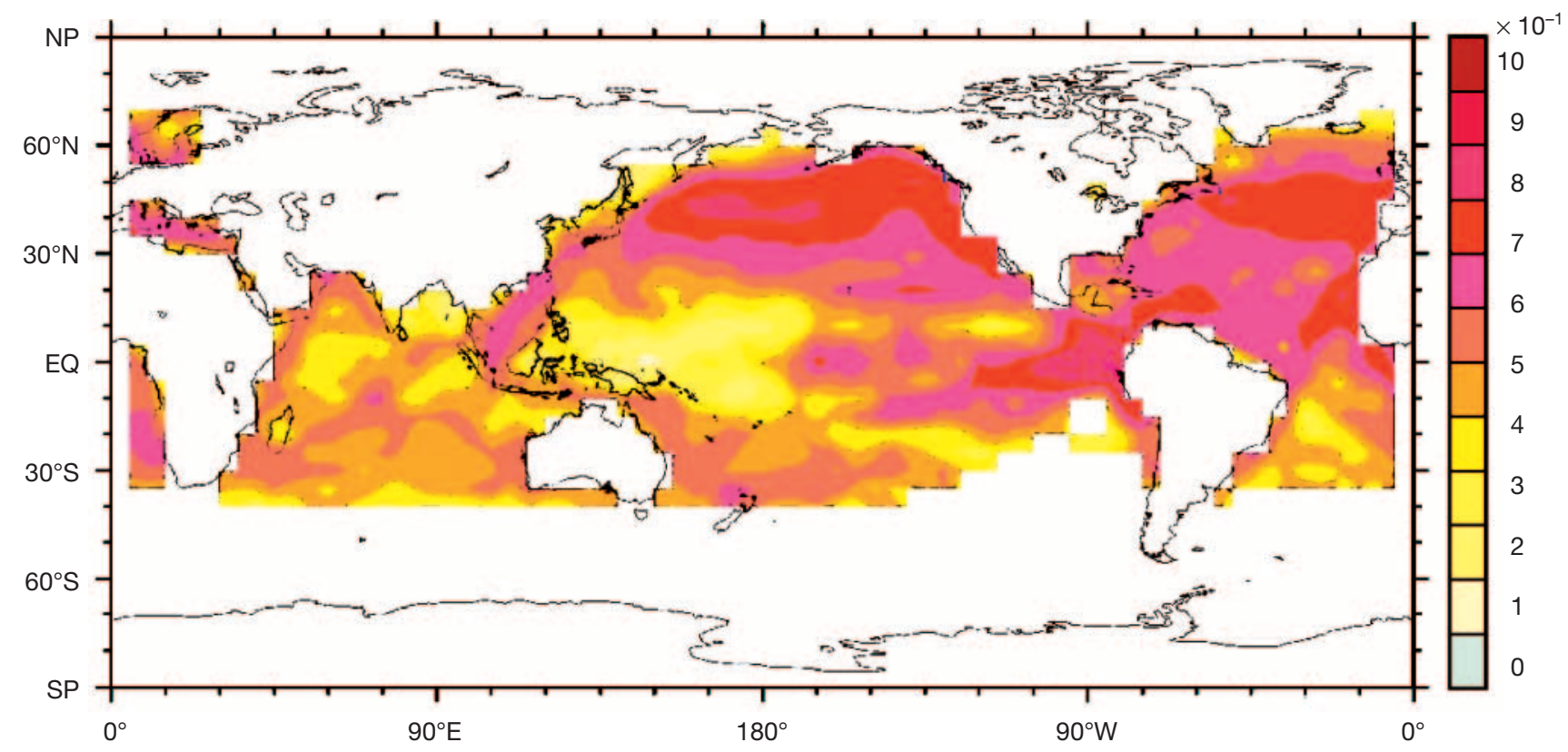

Fig. 3. Correlation between SST and specific humidity at each $5^{\circ} \times 5^{\circ}$ grid cell from 1951-1997

alies of $700 \mathrm{mb}$ pressure heights (Fig. 4) further support mechanisms hypothesized in Fig. 1. Since 1976, low-pressure systems have become more frequent, bringing warm, moist southwesterly winds over the California coast (Trenberth \& Hurrell 1994). Regions influenced by the North Pacific have shown significant climatic changes in recent years (IPCC 1998). It is conceivable that the enhanced amount of atmospheric water vapor may have been partly responsible for the recent asymmetric warming trends that have led to an earlier start of growing seasons over northern high latitudes (Myneni et al. 1997).

As hypothesized in Fig. 1, a strong correlation $(\mathrm{R}=$ $0.82, \mathrm{p}<0.001$ ) exists between Pacific SSTs and coastal California $T_{\text {ave }}$ (Fig. 2). Coastal $T_{\text {ave }}$ also showed significant warming between 1951 and 1997, which we suggest is partly associated with a water vapor feedback. Annual $T_{\text {dew }}$ over coastal California increased by
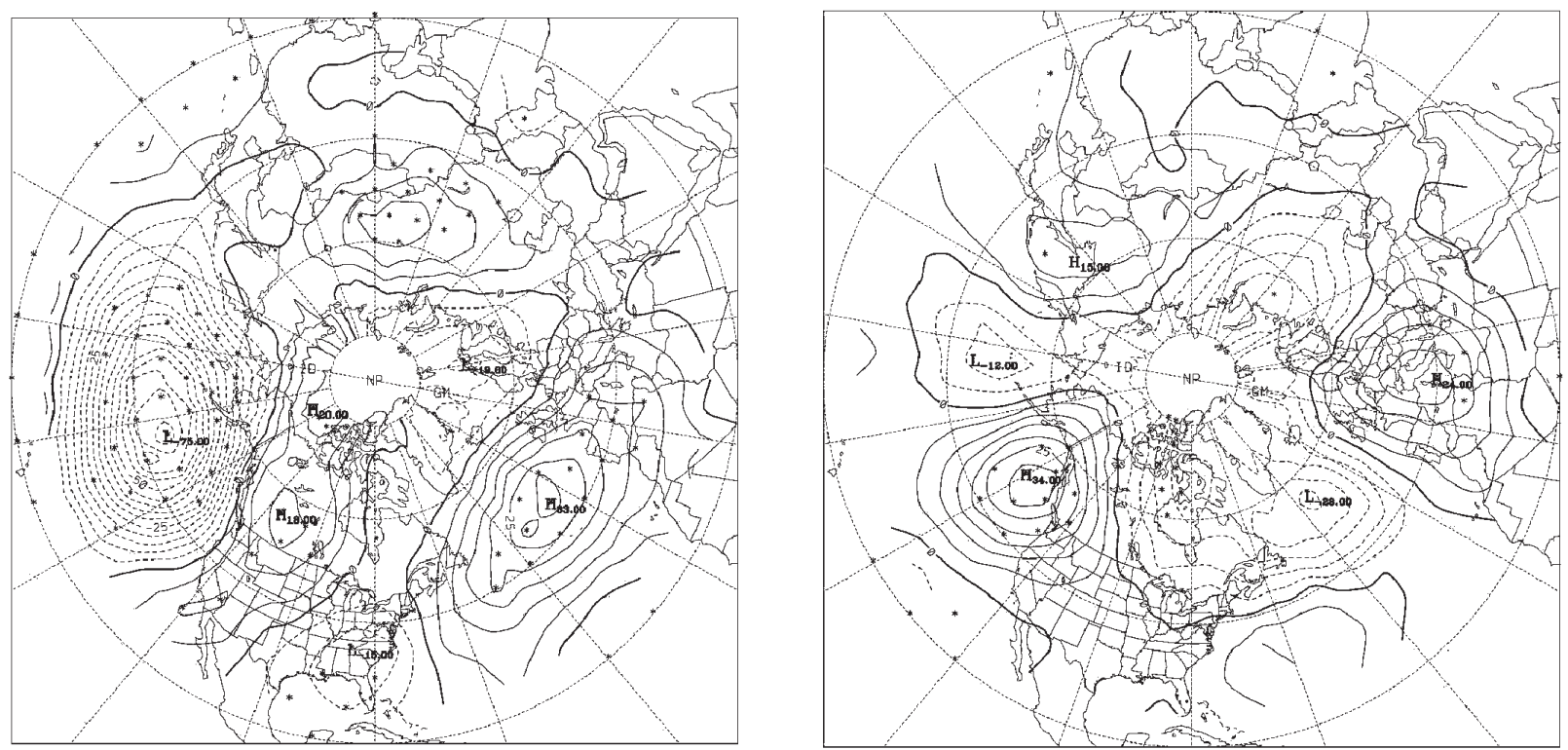

Fig. 4. Winter anomalies of $700 \mathrm{mb}$ pressure heights $(\mathrm{m})$ for high (left panel) and low frost (right panel) frequency years in the Napa and Sonoma valleys 


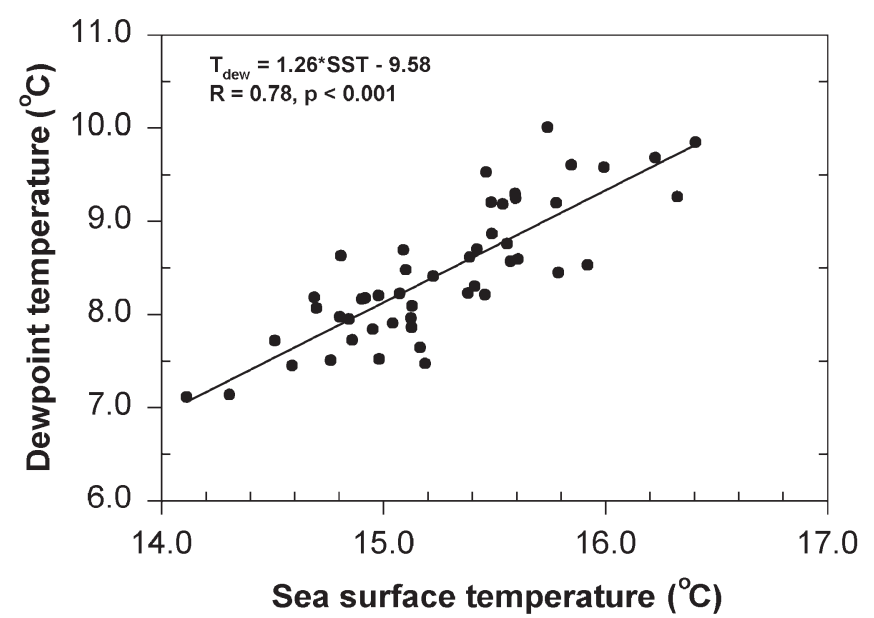

Fig. 5. Observed relation between annual average Pacific SST along coastal California and annual average $T_{\text {dew }}$ measured at the San Francisco and San Diego airports from 1951-1997

$0.97^{\circ} \mathrm{C} / 47 \mathrm{yr}(\mathrm{p}<0.001)$ and was positively related to SSTs (Fig. 5). Gaffen \& Ross (1999) reported similar increasing trends in $T_{\text {dew }}$ and $q$ over much of western North America in recent years. Monthly $T_{\min }$ and $T_{\text {dew }}$ data from 1951-1997 were strongly related $(R=0.96$, $\mathrm{p}<0.001$ ), suggesting a tight coupling between the 2 variables. Increased atmospheric water vapor asymmetrically increased cloud cover. For example, nighttime cloud cover increased 3.4\%/43 yr ( $\mathrm{p}=0.055)$ without significant changes in daytime cloud cover. Increases in nighttime cloud cover may have further enhanced $T_{\min }$ through re-radiation of longwave energy.

\subsection{Asymmetric climatic warming in the Napa and Sonoma valleys}

Consistent with reported global trends, annual $T_{\text {ave }}$ over NSV increased $1.13^{\circ} \mathrm{C}$ between 1951 and 1997. Nearly all the warming was caused by increases in $T_{\min }$ $\left(2.06^{\circ} \mathrm{C} / 47 \mathrm{yr}\right)$, with very little change in $T_{\max }$ (Fig. 6). As a consequence of the asymmetric warming, the DTR declined by $1.87^{\circ} \mathrm{C} / 47 \mathrm{yr}(\mathrm{p}<0.001)$. Such asymmetric changes in temperature have been widely reported for various regions of the globe, and are presumed to be signatures of global warming (Karl et al. 1993, Easterling et al. 1997). It is the asymmetric nature of climate warming, as will be discussed later, that has important implications for agriculture in coastal California. Monthly analysis showed the warming trends to be highly seasonal (Fig. 7). For example, average spring warming was nearly double that of rest of the year. Summer DTR showed the largest decline, supporting earlier results (Karl et al. 1993, Dai et al. 1997).

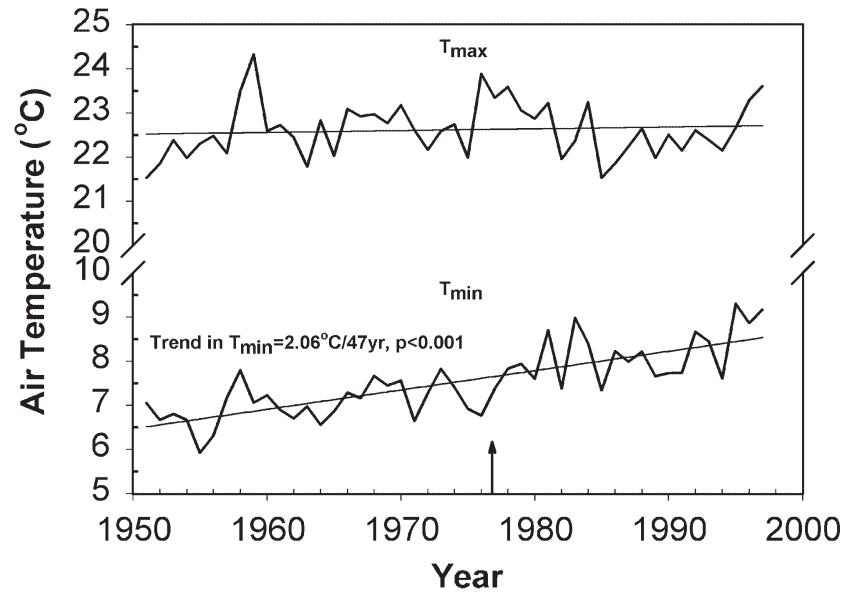

Fig. 6. Annual $T_{\max }$ and $T_{\min }$ trends in Napa and Sonoma valleys

Monthly SSTs showed the largest warming during spring, again confirming the influence of changes over the Pacific Ocean on coastal California climate. Positive trends for $T_{\text {ave }}$ are significant at the $5 \%$ level for all months except December, while negative DTR trends are significant in March, May, July, August, September and October. No significant trends in $T_{\max }$ are found. Positive SST trends are significant in March, April and May. There were no significant changes in monthly or annual precipitation.

It is interesting to note the differences in trends shown in Figs 2 \& 6. Coastal California average temperatures show a shift in magnitude (Fig. 2) coinciding with the shift in Pacific climate. However, $T_{\min }$ (Fig. 6) shows a gradual warming over the entire record (though at a higher rate after the Pacific climate shift, Table 1), suggesting the possibility that additional factors such as air pollution, greenhouse gases and urbanization may be involved.

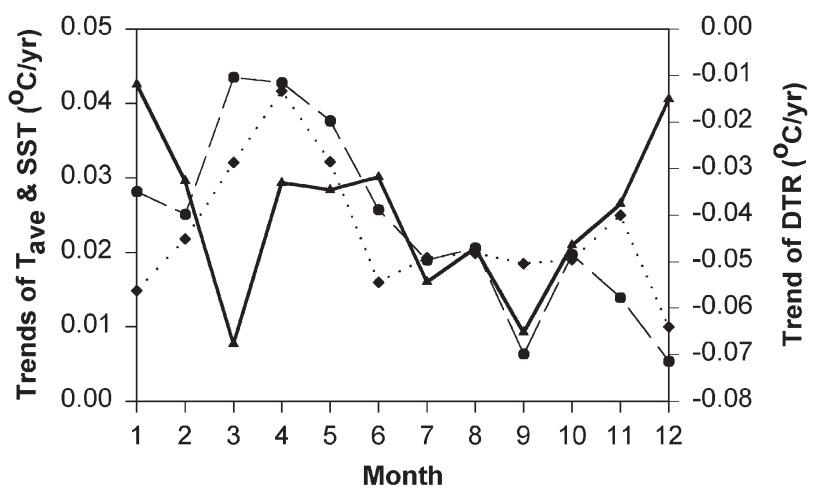

Fig. 7. Napa and Sonoma monthly $T_{\text {ave }}(\bullet)$ and DTR $(\mathbf{\Delta})$ trends from 1951-1997. Monthly trends in Pacific SSTs (•) along coastal California are also shown 
Table 1. Climatic variables important for vintage quantity and quality (Gladstones 1992): 1951-1997 increases; mean and standard deviation $(\sigma)$ before and after the 1976-1977 regional Pacific climate shift (Fig. 2). All differences between periods were significant at the $1 \%$ level ( $t$-test)

\begin{tabular}{|c|c|c|c|c|c|}
\hline \multirow{2}{*}{ Parameter } & \multirow{2}{*}{$\begin{array}{c}\text { 1951-1997 } \\
\text { changes }\end{array}$} & \multicolumn{2}{|c|}{$1951-1976$} & \multicolumn{2}{|c|}{$1977-1997$} \\
\hline & & Mean & $\sigma$ & Mean & $\sigma$ \\
\hline Winter $T_{\min }\left({ }^{\circ} \mathrm{C}\right)$ & 2.39 & 3.74 & 0.88 & 5.06 & 1.16 \\
\hline Spring $T_{\min }\left({ }^{\circ} \mathrm{C}\right)$ & 2.44 & 8.04 & 0.63 & 9.42 & 0.77 \\
\hline Summer DTR $\left({ }^{\circ} \mathrm{C}\right)$ & -3.14 & 19.00 & 0.85 & 17.50 & 0.98 \\
\hline Number of frosts $\mathrm{yr}^{-1}$ & -20.00 & 22.00 & 9.00 & 10.00 & 9.00 \\
\hline Frost-free GSL (d) & 65.00 & 272.00 & 18.00 & 311.00 & 29.00 \\
\hline Growing degree days & 240.00 & 1714.00 & 102.00 & 1830.00 & 112.00 \\
\hline VPD (kPa) & -0.159 & 2.41 & 0.12 & 2.29 & 0.15 \\
\hline
\end{tabular}

Enhanced water vapor shown by increases in $T_{\text {dew }}$, along with small changes in $T_{\text {max }}$, resulted in an estimated $7 \% / 47 \mathrm{yr}$ reduction in growing season VPD ( $\mathrm{p}=$ 0.042). As the VPD are computed using $T_{\text {max }}$ the reported VPD reflect the maximum diurnal VPD. Given the strong diurnal variation in $T_{\max }$ and small variation in water vapor, it is likely that, on average, the VPD reductions would be greater than $7 \%$. Lower VPD reduce evaporative demand and water stress and increase plant growth. The estimated reductions in VPD may have been responsible for the reported decline in pan evaporation over the western US (Peterson et al. 1995).

\subsection{Impact of observed climatic changes on viticulture}

Reported as annual averages, the observed climatic changes in NSV are modest $\left(1.13^{\circ} \mathrm{C} / 47 \mathrm{yr}\right.$ for $\left.T_{\text {ave }}\right)$, but biological consequences can be substantial. For example, the $2.06^{\circ} \mathrm{C} / 47 \mathrm{yr}$ increase in $T_{\min }$ translated to a $71 \%$ decline in frost frequency (from 28 to $8 \mathrm{~d} \mathrm{yr}^{-1}$, Fig. 8). Similarly, a remarkable $65 \mathrm{~d}$ increase in frostfree GSL was caused by a strong decline in already irregular frosts over NSV (from 254 to $320 \mathrm{~d} \mathrm{yr}^{-1}, \mathrm{p}<$ 0.001). Longer growing seasons allow vineyard managers greater flexibility in scheduling various viticultural operations (pruning, harvest, etc.). Though the hypothesis is presumptuous at this point, if the current trends in frost frequency continue, NSV may become a frost-free climate within a few decades. Implications of such large changes in frost frequency and GSL are profound for natural ecosystems, especially for species composition in communities as well as for terrestrial carbon cycles.

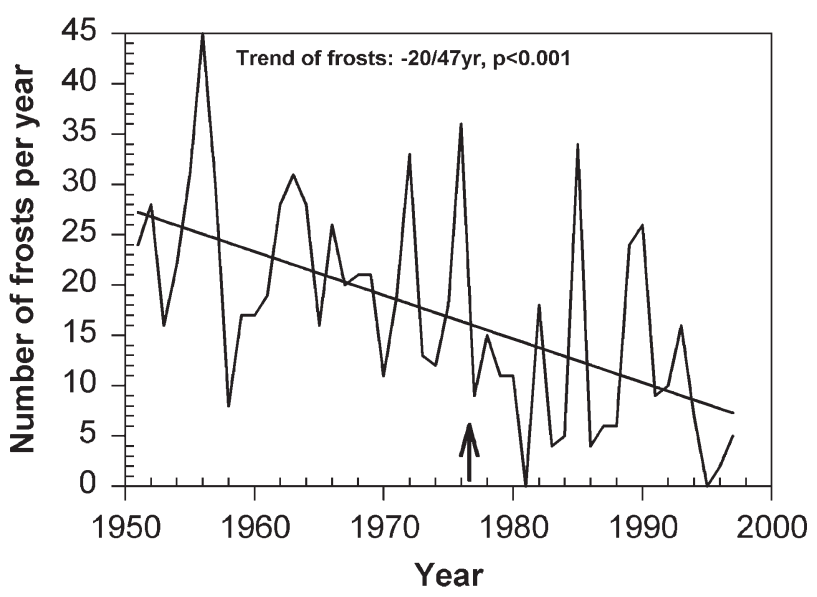

Fig. 8. Observed changes in frost frequency in the Napa and Sonoma valleys from 1951-1997
Observed warming trends increased GDD totals and accumulation rates. Between 1951 and 1997, GDD increased $14 \%$, contributing to higher sugar accumulation and improved quality (Gladstones 1992). Estimated winegrape flowering date showed $24 \mathrm{~d}$ advancement between 1951 and 1997 (Fig. 9). GDD summations also showed that 1600 GDD, the amount required for harvesting grapes for wine making in NSV, were accumulated 20 to 25 d earlier in 1997 than in 1951. Faster accumulation allows vineyard managers to leave the grapes on the vines until the optimal balance of sugars and acids is achieved.

Warmer winter and spring temperatures in NSV also advanced honeysuckle flowering by $18 \mathrm{~d}$ between 1968 and 1994 (Fig. 9). Estimated winegrape flowering and measured honeysuckle flowering are correlated $(\mathrm{R}=0.58, \mathrm{p}<0.001)$, suggesting that in spite of microclimate differences, both datasets show similar responses to climatic variability.

Temperature variability and temperature extremes, as measured by the temperature variability index (TVI, Gladstones 1992), are related to wine quality,

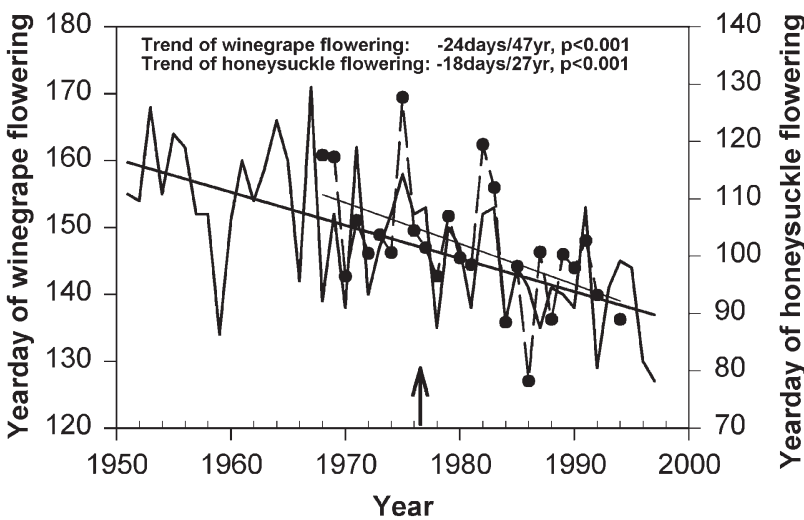

Fig. 9. Estimated winegrape (-) and measured honeysuckle (•) flowering dates. Data for honeysuckle flowering is not available for 1993 
TVI $\left({ }^{\circ} \mathrm{C}\right)=\sum\left[\left(T_{\mathrm{D} \max }-T_{\mathrm{D} \min }\right)+\left(T_{\mathrm{M} \text { max }}-T_{\mathrm{M} \text { min }}\right)\right]$

where $T_{\mathrm{D}}$ and $T_{\mathrm{M}}$ represent daily and monthly temperature values between March and October. Low TVI favor high-quality wines. In NSV, the TVI declined from 36.1 in 1951 to 31.4 in 1997. TVI values under 30 indicate that any variety of table wine may be produced. Locations within a vineyard that maintain higher $T_{\min }$ and low DTR as a result of soils or topography are regularly associated with high-quality wines (Johnson 1985). Observed climatic changes (Fig. 7) are likely to have similar positive influence on wine quality for entire vineyards.

Greenhouse experiments show that higher $T_{\min }$ and low DTR produce large berries of high quality (Kobayashi et al. 1967). Crop simulation models showed low DTR to increase yields of maize, soybean and wheat (Dhakwa \& Campbell 1998). While the mechanisms for such a positive influence of high $T_{\min }$ and low DTR are yet unclear for temperate crops, high nighttime temperatures are generally associated with enhanced cell division and plant growth (Coombe 1987). Agronomic practices (irrigation, fertilization, etc.) are widely used to increase the amount of photosynthesis during day; however, climate seems to have the ultimate effect on nighttime biochemical processes. Therefore, observed asymmetric warming is likely to help temperate crops as long as $T_{\min }$ continues to be in the optimum range.

\subsection{Have recent climatic changes helped the California wine industry?}

Wine quality ratings ( $0-100$ scale) by Sotheby's (Stevenson 1997) increased by 7.5 points/34 yr (Fig. 10, $\mathrm{p}=$ 0.022) between 1963 and 1996. Annually updated ratings, such as the Wine Advocate vintage charts for north coast California wines (Parker 1997) show similar trends, as do all long-term datasets of California wine quality. Among the variables listed in Table 1, the decline in frosts especially during winter months was found to be strongly associated with increasing wine ratings. Correlation of detrended data for both frosts and wine quality yielded an $\mathrm{R}=0.64$ with $\mathrm{p}<0.001$, suggesting a weak albeit significant relation. A possible explanation for such a relation could be that frosts damage buds on the vine, delaying subsequent phenological events and leading to uneven maturity and poor wine quality. Years with low frost occurrence also showed warm springs and low summer DTR, both of which promote wine quality (Coombe 1987).

Napa winegrape yields grew from 7.3 to $9.8 \mathrm{t} \mathrm{ha}^{-1}$ (34\%) between 1963 and 1996, suggesting that high yield and high quality are not mutually exclusive. Increases in spring $T_{\min }$ and decreases in summer VPD explain more than $56 \%(R=0.75, p<0.001)$ of the upward trend in Napa yields. In Napa valley, consequent with increasing quality and quantity, the value of the grape crop increased from $\$ 640 \mathrm{ha}^{-1}$ in 1963 to $\$ 19600$ ha $^{-1}$ in 1996 (Napa County Agricultural Commissioner 1997).

All parameters shown in Table 1 exhibit pronounced changes over the 1951-1997 record, especially since the 1976-1977 shift in Pacific climate (Fig. 2) (Ebbesmeyer et al. 1990). Before 1976, a number of vintages had poor ratings associated with frequent frosts (Fig. 10). However, after 1976, wine ratings steadily improved with the near disappearance of frosts (Fig. 8). Warmer SSTs after 1976 (Fig. 2), coupled with low sea level pressures enhancing the warm, moist southwesterly winds during 1977-1988 (Trenberth \& Hurrell 1994), resulted in an unprecedented string of years with high wine quality. Similar warming trends accompanied advancement in phenological events and better sugar:acid ratios in Bordeaux, leading to higher wine quality over the last 2 decades (Jones 1999).

Given the limitations of yield and quality datasets used, it is difficult to argue unambiguously as to how much changes in climate have helped the wine industry relative to the adaptation of new technologies. However, the cumulative evidence (past viticultureclimate research, observed changes in climate in NSV, and trends in winegrape yield/quality of NSV) points to a positive role played by recent climatic changes.

\subsection{Implications for the future of the Californian wine industry}

Unfortunately, along with the positive effects from recent climatic changes, there could be future negative impacts for the wine industry. Although NSV humidity levels are currently optimal (Gladstones 1992), trends

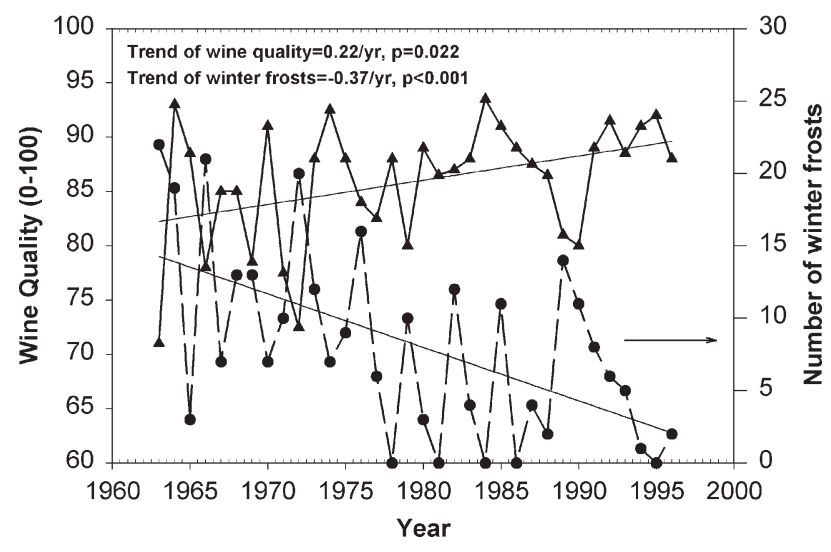

Fig. 10. Inter-annual variations in wine quality and number of frosts 
toward increasing humidity and air temperature suggest that in the future the risk of fungal and vectorborne disease outbreaks may increase. Pierce's disease, a fatal bacterial (Xylella fastidiosa) disease transmitted by sharpshooter beetles (Cicadellidae family) and apparently limited by frost occurrence, is increasing in NSV. Climatic change may therefore require increased investment in pesticide application and disease-resistant rootstock.

Given the strong coupling between Pacific SSTs and the coastal Californian climate, and because regionalscale SSTs persist for 6 to $12 \mathrm{mo}$, additional research may allow the possibility of predicting vintage quantity and quality from previous winter conditions. For example, winters characterized by warmer SSTs and frequent low-pressure systems over the Pacific generally resulted in higher quality wines.

The Pacific Decadal Oscillation (PDO), reflecting changes in North Pacific climate, has been found to be strongly associated with a number of environmental changes over coastal regions of north America (Ebbesmeyer et al. 1990, Mantua et al. 1997). During the 1976-77 shift, the PDO changed from a low (negative) to a high (positive) phase. Our analysis of variations in wine quality with PDO indicates that high PDO years have all been associated with above-average wine quality (1963-1996). Incidentally, much of the recent growth in the Californian wine industry occurred during the positive phase of the PDO. The mechanisms behind the PDO and its predictability are poorly known at this point; however, a shift back to the low phase may bring climate-related challenges to the wine industry.

\section{SUMMARY}

Significant climatic changes from 1951 to 1997 were found in the premium wine-producing areas of NSV. The asymmetric nature of the observed warming could be traced to increases in SST and water vapor over the Pacific Ocean. Asymmetric warming, in turn, was found to be responsible for widespread changes in frost frequency, growing season length, and vapor pressure deficits. According to past viticulture-climate studies, many of the observed changes were found to benefit California viticulture (Gladstones 1992). Consequent with the observed climatic changes, trends in both yield ha $\mathrm{h}^{-1}$ and wine quality of California vintages over the last 3 decades have shown substantial improvement.

Observed climate trends may not continue to be as beneficial to the California wine industry, as the possibility of increasing pest/disease outbreaks is likely to increase.
Acknowledgements. This work was performed while R.R.N. was a National Research Council Fellow at the NASA/Ames Research Center. We thank Lee Johnson of NASA/Ames, David Graves of Saintsbury Winery, and 3 anonymous reviewers for their insights and suggestions. Funding from NASA's Earth Science Enterprise supported this research through an Earth System Science Fellowship to M.A.W. and grants to S.W.R. and J.C.C. D.R.C. was supported by grants from the NOAA Office of Global Programs.

\section{LITERATURE CITED}

Caprio M (1993) A collection of the annual reports to cooperators of the phenological survey in the western region of the United States and related phenological information for the period 1956-1992. Montana Agricultural Experiment Station, Bozeman, MT

Chahine MT (1992) The hydrologic cycle and its influence on climate. Nature 359:373-380

Coombe BG (1987) Influence of temperature on composition and quality of grapes. Acta Hortic 206:23-35

Dai A, Del Genio AD, Fung IY (1997) Clouds, precipitation and temperature range. Nature 386:665-666

Dettinger MD, Cayan DR (1995) Large scale atmospheric forcing of recent trends toward early snowmelt runoff in California. J Clim 8:607-623

Dhakhwa, GB, Campbell CL (1998) Potential effects of differential day-night warming in global climate change on crop production. Clim Change 40:647-667

Easterling DR, Horton B, Jones PD, Peterson TC and 7 others (1997) Maximum and minimum temperature trends for the globe. Science 277:364-367

Ebbesmeyer CC, Cayan DR, McLain DR, Nichols FH, Peterson DH, Redmond KT (1990) 1976 step in the Pacific climate: forty environmental changes between 1968-1975 and 1977-1984. In: Betancourt JL, Tharp VL (eds) Proc 7th Annu Pac Clim (PACLIM) Workshop. Interagency Ecol Stud Prog Tech Rep 26, California Department of Water Resources, Sacramento, CA, p 115-126

Gaffen DJ, Ross RJ (1999) Climatology and trends of U.S. surface humidity and temperature. J Clim 12:811-828

Gladstones J (1992) Viticulture and environment. Winetitles, Adelaide

Intergovernmental Panel on Climate Change (IPCC) (1995) The science of climate change. Cambridge University Press, Cambridge

Intergovernmental Panel on Climate Change (IPCC) (1998) The regional impacts of climate change: an assessment of vulnerability. Cambridge University Press, Cambridge

Jackson DI, Lombard PB (1993) Environmental and management practices affecting grape composition and wine quality: a review. Am J Enol Vitic 44:409-430

Johnson H (1985) The world atlas of wine, 3rd edn. Simon and Schuster, New York

Jones GV (1999) Relationships between grapevine phenology, composition, and quality for Bordeaux, France. Arbor Phaenol 42:3-7

Karl TR, Jones PD, Knight RW, Kukla G and 6 others (1993) A new perpective on global warming: asymmetric trends of daily maximum and minimum temperature. Bull Am Meteorol Soc 74:1007-1023

Kobayashi A, Fukushima T, Nii N, Harada K (1967) Studies on the thermal conditions of grapes: effects on day and night temperatures on yield and quality of Delaware grapes. J Jpn Soc Hortic Sci 36:373-379

Laube J (1996) Wine Spectator's california wine. Wine Spec- 
tator Press, New York, NY

Livezey RE, Smith TM (1999) Covariability of aspects of North American climate with global sea surface temperatures on the interannual to interdecadal timescales. J Clim 9: 289-302

Mantua NJ, Hare SR, Zhang Y, Wallace JM, Francis RC (1997) A Pacific interdecadal climate oscillation with impacts on salmon production. Bull Am Meteorol Soc 78:1069-1079

McGowan JA, Cayan DR, Dorman LM (1998). Climate-ocean variability and ecosystem response in the Northeast Pacific. Science 281:210-217

McIntyre GN, Kliewer WM, Lider LA (1987) Some limitations of the degree day system as used in viticulture in California. Am J Enol Vitic 38:128-132

Myneni RB, Keeling CD, Tucker CJ, Asrar G, Nemani RR (1997) Increased plant growth in the northern high latitudes from 1981-1991. Nature 386:698-702

Napa County Agricultural Commissioner (1997) 1951-1997 annual crop reports. Napa County Department of Agriculture, Napa, CA

Parker R (1997) The Wine Advocate's vintage guide,

Editorial responsibility: Roger Pulwarty,

Silver Spring, Maryland, USA
1970-1997. The Wine Advocate, Monkton, MD. Available at http://www.winetech.com/html/vintchrt.html

Peterson TC, Golubev VS, Groisman PY (1995) Evaporation losing its strength. Nature 377:687-688

Plantico MS, Karl TR, Knight RW (1994) Is recent climate change across the United States related to rising levels of anthropogenic greenhouse gases. J Geophys Res 95: 16617-16637

Raval A, Ramanathan V (1989) Observational determination of greenhouse effect. Nature 342:758-761

Stevenson T (1997) The new Sotheby's wine encyclopedia. DK Publishing Inc, New York, NY

Trenberth KE, Hoar TJ (1997) El Nino and climate change. Geophys Res Lett 24:3057-3060

Trenberth KE, Hurrell JW (1994) Decadal atmosphere-ocean variations in the Pacific. Clim Dyn 9:303-319

Went FW (1953) Effect of temperature on plant growth. Annu Rev Plant Phys 4:347-362

Woodruff SD, Slutz RJ, Jenne RL, Steurer PM (1987) A comprehensive ocean-atmosphere data set. Bull Am Meteorol Soc 68:1239-1250

Submitted: November 3, 1999; Accepted: February 13, 2001 Proofs received from author(s): August 29, 2001 